\title{
Issues in the relationship between technology and practice
}

\author{
Sarah Porter* \\ Foint Information Systems Committee, UK
}

The paper explores some of the key themes and discussion points that were aired at the Association of Learning Technology conference in 2004. It discusses the findings of several of the keynote speakers and presenters within the context of the relationship between technology, practice and innovation. It references the papers presented in the technology infrastructure and new technology strands of the conference to examine whether educational technology currently has an appropriate balance between innovation and good practice. It then presents a case study of application in practice through some of the development activities that a national funding body, the JISC, has put into place. Finally, it draws conclusions about how well the learning technology community is achieving appropriate balance between innovation and technology.

This discussion piece reflects on the papers presented at ALT-C 2004 that were under the 'technical infrastructure' and 'new technology' strands of the conference. The theme of the conference focused on looking forward to the future: 'learning technologies for the next decade', with a bridging subclause that connected two seemingly contradictory or conflicting terms 'blue skies and pragmatism'. There are a highly complex set of relationships between 'innovative', 'risky' or 'blue skies' technology and its effective use in supporting practitioners or 'pragmatism'. It may seem a challenging question to ask at a conference that is focused on technology, but from the opening keynote we were asked indirectly to focus upon the question: 'why innovate?' (Kumar, 2004). Kumar reached the conclusion that we should not simply innovate for the sake of it but in order to offer an improved or even an extended and better experience: 'Technology doesn't just allow students to answers questions more quickly, but to ask new questions' (Kumar, 2004). This sets the tone for some of the most fascinating discussions of the conference, such as: What should be the relationship between technology and practice? Should technology stimulate innovation in practice or should technology support practice? Or is it able to do both? At what point

\footnotetext{
*Joint Information Systems Committee, King's College London, Strand Bridge House, 138-142 The Strand, London, WC2R 1HH. Email: s.porter@jisc.ac.uk
} 
should innovation become 'embedded' into practice and how can this be achieved? This discussion piece will reflect on the extent to which these questions were addressed in the papers at the conference.

In the opening session of the conference I was asked to give a brief overview of what I saw as the key issues for 'my' conference themes- 'Technical infrastructure' and 'New technology'. In order to further explore these relationships during the apparently most technically-focused sessions of the conference, I focused upon the complex relationship between people and technology and posed three questions that I hoped we would be in a better position to answer by the closing session at the end of the conference. The three questions were:

- Is technology changing practice?

- Is it improving the student learning experience?

- Do we have the balance right between technology and practice?

To illustrate the tension and compromise that is inherent in the final question, I used a simple diagram; a vertical axis labelled technology, a horizontal axis labelled practice, and a dotted line that mapped a diagonal line between the two that was labelled 'innovation'. The implication of the diagram was that in continuing to move forward with both technology and practice, we should innovate in both areas, while also attempting to maintain a balance between innovation in practice and innovation in technology. Technology should not dominate this progress, but neither should we assume that practice will not change over time; both should co-evolve.

During many of the sessions in both the technology and technical infrastructure strands, I attempted to pursue the issue of the relationship between innovation, technology and practice. It was fascinating to discover that, in drawing their conclusions, many of the speakers focused upon the intersection and tension between two or all three of these themes. Through the sessions, we began also to illuminate and, to some extent, to address the questions that I posed in the opening session.

\section{Is technology changing practice?}

There were numerous examples given during the papers of how technology is influencing practice, for example Keefe's (2004) paper on the way in which mobile technology offers potential for more personalised learning. However, this was tempered with the realisation that there was a need for practitioners to evolve their own practice through engaging in experimentation and that practitioners need to go through their own cycle of evolution to change the way they work. As Gunn (2004) pointed out 'However many examples of good practice there are, people need to learn from their own process of trial and error'.

It was also acknowledged that in some cases engagement with technologies will actually result in practitioners finding a solution to problem, precisely because they want to try something new. The conference papers included many examples of how technology is changing practice; for example, Keefe's (2004) paper on mobile technologies demonstrated that they enabled a more 'populist and personal approach' to 
learning. This suggests, therefore, that there is evidence that technology is changing practice, but that the relationship between the two is complex and interdependent.

\section{Is technology improving the student learning experience?}

Reference to the learning experiences of students was not the main focus of many of the presentations I attended. However, several presentations referred to a general improvement in the student experience, although not specifically their learning experience. A good example of this improvement is the way in which technology can be used to encourage teachers and students to be more reflective (e.g. through appropriate use of discussion forums or e-portfolios). In his fascinating and engaging session on personal development planning, Rowsell drew upon his own experience to describe how art students improved their practice as learners by encouraging more reflection; by using SMS technology, or 'moblogs' (mobile logs), to build up journals, thus reflecting on their practice. He concluded that: 'technology can make you a better teacher and a more reflective learner' (Rowsell, 2004).

There were other issues that focused on the relationship between technology and the student or practitioner experience. There was a theme across several sessions suggesting that technology could improve interaction by providing enhanced forms of communication. McCabe referred to using technology to act as an intermediary between student and tutor'. Heins referred to the fact that learners and teachers want technology that can afford the same kind of serendipitous communications that we experience in face-to-face settings- - these are sometimes termed 'water cooler encounters' (Herbsleb et al., 2002). However, there were also indications in some of the papers that communications tools have not yet evolved enough to offer the richness of communication that is required, suggesting that the way we currently use communication tools has not evolved enough. Flanagan et al. (2004) suggested that tools are used for 'connecting not communicating'-the implication being that current technologies allow people to share information, and not the more complex levels of communication that are possible in face-to-face interactions. However, there were examples given of how technology could improve the student experience; for example, through the use of interactive classrooms as a means of engaging learners (McCabe \& Lucas, 2004).

\section{Do we have the balance right between technology and practice?}

Interestingly, the sessions I attended did not generally address the question of whether the balance between technology and practice is right. What emerged instead was the close relationship between changes in technology and changes in practice.

A number of presentations drew conclusions about the systemic use of technologies, reflecting on questions such as how can institutions and practitioners move from a situation where technology is being used in a marginal way for experimentation to consistent and widespread usage? Examples were given of where technology is now being used to support some of the core functions of institutions; virtual learning environments are the obvious example and, in fact, in contrast to presentations at 
previous ALT-C conferences, few presentations focused on their actual implementation, which suggests that these technologies have now become so mainstream that they are not worthy of much comment. Other presentations looked in some detail at specific examples of technology becoming an integral part of learning, teaching and administrative processes. Fitzgerald (2004), for example, examined how electronic submission of coursework is now a standard part of the processes of learning and teaching. This change has challenged a lot of current processes in ways that had not previously been predicted. Although there is lot of enthusiasm from students and staff to use the new systems because they are perceived as being more efficient and effective, these innovations (in both technology and practice) will ultimately lead to significant changes to university systems and processes. This suggests that the introduction and use of a technology will always force new processes and practices and that the two things (technology and practice/processes) cannot be separated.

The ALT-C audience is largely made up of those who are trying to engage practically with new technologies and processes and those who are concerned with supporting effective change. Several of the presentations reached thoughtful conclusions about how to best manage the implementation of innovative technologies and shared some good advice with their peers. One issue that was raised was that of scalabilityinnovations that are highly successful in small groups may not be effective when they are rolled out to large groups; the conclusion that can be drawn from this is that we need to consider 'scaling up' issues when creating a plan for the introduction of a technology. Issues of scale may be affected by either the limitations of technology per se or by associated human and organisational issues. A further, slightly controversial, point made was that practitioners may think that innovative technologies lose their 'fun' when they move from small-scale to large-scale implementation. To some extent this suggests that one of the enablers for practitioners looking at the use of new technologies is its 'novelty factor' rather than the improvement in quality or enhancement of the student learning experience that might result. However, this is perhaps more a question of the level of saturation of the technology within the learning process rather than whether the technology is scaled up to widespread use. So a technology may still be considered exciting if it is used by many students, but its use becomes mundane and routine when it is used across all aspects of a student's course.

Some papers also pointed out that funding allocations and cost models will also affect the uptake of technologies. Planners should also be aware that some technologies are both cost-effective and readily available - in particular, technologies such as mobile phones, where there is almost $100 \%$ ownership by the student population (Traxler, 2004). Availability will affect how readily a solution based on that technology can be rolled out.

A further, more theoretical, theme that appeared in a number of sessions, related to the technological philosophy that underpins many of the current technologies. The point was made several times that few technologies were designed explicitly for educational use. Examples include computers, telephones and Personal Digital Assistants. One of the most widely deployed 'educational' technologies, the Virtual Learning Environment or Learning Management System, is in reality little more than a 
slightly adapted content management system, where the educational use is 'bolted on'. This suggests that the technologies that are being promoted for use in education actually have a business rather than an educational focus. There was some debate in the discussion session at the end of the conference about whether such adaptation of technology for a different purpose is necessarily a problem. Some felt that the fundamental business philosophy that underpins some technologies, where the main driver is to increase information retention rather than understanding, might conflict with more philosophical and moral educational ideals. However, the overall impression gained from the conference presentations was that people are adapting technology to do what they want it to: interactive classroom technologies, for example, were not designed for educational use but are supremely well-suited to engaging learners in active discourse and reflection. Jones (2004) spoke of 'technology appropriation', and this supported the slightly subversive tone that represented the overall trend: educationalists are using their knowledge and experience to get technology to do what they think is appropriate.

There were also a number of papers that questioned the technical and philosophical concepts that underpin some of the most widely used technologies. Presentations such as the Multi-user Online Dynamic Environment for Learning paper questioned current technologies and underlying models upon which they depend (Brenton, 2004). Other papers focused on practical issues, for example on how we adapt and develop current systems, and explored some of the current trends in technology that are receiving a lot of recognition at present. Morrison (2004) spoke of the serviceoriented approach to systems integration and information transfer that he suggested might be the 'next big thing', a fact that is of central relevance to the current Joint Information Systems Committee (JISC) e-Framework programme. Morrison supported adoption of an approach based on a more flexible component-based system, rather than implementation of a complete, all in one, e-learning system. However, he did pose an important question about the timing of these developments, asking whether is it too soon or too late to begin to promote this approach, when many universities are already committed to large, off-the-shelf systems.

Many presentations acknowledged the fact that innovation is difficult and that introducing a new technology to an organisation can cause many problems. A 'blue skies' technology cannot be easily introduced into existing closed and protected IT systems that are prevalent in most institutions; there is an inherent resistance to such implementation and support for technologies that are perceived to be untested and potentially risky. This is completely understandable; IT support services are put under increasing pressure to provide streamlined, efficient and reliable services; many support services have to meet strict targets for service support. New technologies that stress these systems (or stress the staff who have to support their use) introduce additional risk into an already overburdened organisational system. Many universities do not have capacity to pay for the increased level of support needed to cope with this risk. This leads to the conclusion that institutions may stifle innovation-because they do not have sufficient financial or human resources to support innovation. There is also the possibility that in some cases an institution (or some of the stakeholders 
within the institution) may not wish to innovate; as it was put more bluntly in one presentation, 'innovation stops as soon as the administrators get involved' (Elliott, 2004) - although some might argue that this is an extreme and contestable statement.

Any innovation that is to prove its value to practitioners has to move from being innovative to becoming embedded into practice and into organisational processes. This can be summarised as a cycle of adoption for innovation: 'From innovation to normalisation'. Several presentations referred to the iterative development cycle that tends to be followed during successful innovation. This was captured in some of the sessions in terms of the 'cycle of adoption' for technology. Several presenters referred to the fact that innovation occurs at many points in this cycle; and that it tends to be driven by a specific problem that needs to be addressed, as well as the people (practitioners, managers or support staff) who are willing to try something new to address the problem.

There seems to be a further relationship between successful innovation and increased use of technology leading to more embedded or systemic usage. In his presentation, Keefe (2004) highlighted that, for an innovative technology to be taken up to the point it needs to become embedded or systemic, the concept behind the innovation needs to be proven. So it appears from the experiences recounted that the more cutting edge or 'blue skies' technologies make demands on organisational systems and processes, on cultural norms and practices, and on learning and teaching practices.

The conference sessions supported the well-elaborated discussion about how best to introduce change into an organisation. The importance of recognising the need for change was echoed through many presentations. It was widely recognised that the introduction of new and innovative technologies (and supporting processes) will require both planned and unplanned changes to occur. These changes will often need to take place in locations within the university system that are seemingly remote from the technology; this makes the change requirements more difficult to predict. These themes were further elaborated and explored during the open discussion session on the final day of the conference, at which I drew together some of these conclusions. Many of the delegates at the conference are actively engaged in trying to move innovative, experimental use of technology towards a state of being pervasive or systemic. Participants identified some of the barriers to this change, focusing particularly on the problem of the lack of high-level support for innovatives and technology implementation within institutions.

Keefe (2004) drew upon his experience working for the University for Industry in setting up the LearnDirect service, which has several million learners. His conclusion was that the education sector is not generally good at making business cases and thinking through the implications of making a change, and that we could learn a lot from business environments or more delivery focused organisations such as LearnDirect in addressing difficult questions about why change is needed and what benefit it will bring. Benefits may not necessarily be financial, but could be about an overall improvement in quality, or increased student retention or satisfaction; whatever the benefits, institutions need to be clearer about why they think a change is needed. This 
is particularly important when investment and support are needed from the senior management; which is problematic given that senior management were frequently cited in the papers as being inherently conservative and change-averse.

We need also to be aware of what we may lose when introducing change- - not all change is positive-and this should be included in an analysis of the implications of introducing new technologies into an institutional or organisational environment, and any business case for the introduction of new technologies should look at potential negative as well as positive impacts. Senior managers are more likely to be influenced by a balanced argument than an unrealistically positive view.

Keefe's points were contradicted to some extent in Morrison's presentation, where there was a recognition that, internationally, some universities are becoming more corporate, in part because they are responding to government imperatives for a more market-driven education system (Morrison referred to James Cornford's (2000) paper on the 'Virtual University').

A further negative implication is that we may lose something when technology becomes systemic. In the closing session, Sloep (2004) talked about the 'dullifying' that might be implied when technology becomes systemic; and warned that the sense of ownership and personalisation may be lost. This reiterates the point made earlier that the motivational drive to using technology may be less effective if the technology is used across all aspects of the learning experiences. Thus, the introduction of any new technology needs to consider the student experience as a whole, rather than focusing upon discrete chunks of learning, and should attempt to create a balanced picture.

\section{A case study of application in practice-the JISC approach}

In light of the above review of the technological-related papers at the conference, this section provides a summary of some of the ways in which one national funding body in this area, the JISC, is attempting to address many of the issues highlighted in the conference papers.

For the past 10 years, the JISC has stimulated innovations in both technology and practice. In the early 1990s, the JISC funded early experiments with Virtual Learning Environments, such as Colloquia and COSE, which are still considered to offer richer and more flexible environments for learning and communication than many widely deployed learning environment systems. In parallel, the Electronic Libraries (or eLib) programme made significant strides in developing our understanding of digital libraries. Many of the projects funded have gone on to form part of the (at the time) nascent institutional digital library, while others contributed to services that are still running, such as the Ariadne e-journal.

These early JISC programmes, which focused on innovation in technology, were followed by projects that considered both the technical and organisational/cultural issues. For example, the Managed Learning Environment programme worked with institutions to explore the issues of integrating institutional systems and processes in order to support improved learning and teaching processes. What emerged was that 
the main barriers to integration were not technical but were, once again, cultural and organisational. The message from the Managed Learning Environment programme was that change needs to be both top-down and bottom-up if it is to succeed and, as has been iterated numerous times, change needs to be closely tied to institutional strategy and imperatives - even if, at times, the strategies need to be written and the imperatives identified by those attempting to achieve the change rather than senior managers.

These examples outline some of the approaches that the JISC has taken in order to stimulate innovation in both technological advances and in organisational and social practices. One of the desired outcomes is to help organisations make the most effective use of technology that is appropriate to their own institutional goals. Activities like the Managed Learning Environment programme, which directly engage stakeholders at all levels within institutions in developing a strategic and integrated approach to the use of technology to support learning and teaching and, to some extent, improved administrative processes, help to achieve this goal. On one level, such programmes help institutions to develop and create a more knowledgeable workforce that is experienced with planning and implementing innovations within a formal project management structure, and ultimately to increase the capacity of the UK education sector to manage innovation more effectively. On another level, the programmes provide demonstrations of what can be achieved within an institution, if resources are made available and if support and advice is provided. The programmes can provide exemplars of good practice or, at the very least, provide evidence of the problems encountered when trying to take a systemic approach to a particular technology.

However, the JISC is aware of the limitations of its funding and that there will always be a situation where some institutions will be more directly engaged in its activities than others. In order to ensure that the 'sum of the whole is greater than the parts', programmes focus on specific themes, such as re-using learning objects or regional partnerships. This means that at times there may not always be a direct alignment with what is happening within institutions. The JISC is exploring different approaches to addressing this problem. We have already begun to address this issue through funding programmes such as the e-learning programme, which has several different strands of activity, ranging from pedagogy and e-learning through to innovative technologies, in order to provide a range of possible points of interaction with different groups. The programme also used an expert consultation group (derived from across the community), along with an actively edited web site that synthesised the conclusions emerging from each of the strands into a coherent whole. Instead of funding lengthy programmes of a single set of projects, the approach has been to fund short-term projects in sets of cycles, where outcomes can be captured early and shared-for example, through the 'Effective Practice in e-Learning' publication that was published in 2004 .

We want to develop these approaches further, looking at a range of methods to better engage the education community in the JISC's activity, so that our programmes can be more closely aligned with the most urgent priorities, as well as predicting the issues that will become important over the next five years. 
In particular, the next year will focus on the issue of community engagement with JISC programmes through the development of the e-Framework. The primary goal of the initiative is to produce an evolving and sustainable, open standards-based service-oriented technical framework to support the education and research communities. Although the e-Framework can be conceived as a largely technical development, the most important strand of activity that is being developed at present is the concept of domain and reference models. The intention is to capture in a consistent format the processes and functions that are commonly present in education and research, and use these to determine the activities that should be funded. The eFramework is being designed to support research processes and administrative processes as well as learning and teaching, so the intention is that the mapping that will be done will help to identify where there are common processes across the domains and ensure that resources are being used effectively to share practices. The ultimate goal is to better engage the community in prioritising the activities that the JISC committees choose to fund; we hope that appropriate models for community engagement can help us to achieve this, and to help close the gap between innovation in technology and in practice.

\section{Conclusions}

The conclusion that can be drawn from the presentations and the final discussion session at the conference is that, although the papers were in theory focused upon the most ground-breaking and innovative uses of technology in education, the crux points in most sessions were issues of organisational and cultural change. The most lively discussion topic in the closing session was around the subject of how we can achieve large-scale uptake of successful innovations within our organisations. The learning technology community is already very sensitive to issues of organisation and culture, and is expert in bridging the gap between the technology and the practitioner. However, are we perhaps less expert in 'selling' our message? What are the benefits that can be brought about by the introduction of changes in technology and practice? What are the risks and the costs? We need to get past these hurdles if we are to see significant adoption of learning technology in our institutions.

Do we then have the balance right between innovation in technology and practice? The conclusion here seemed to be that we cannot separate out innovation in technology from innovation in practice, but, as a community, we need to become better at stimulating the right kind of innovation in both technology and practice.

\section{References}

Brenton, S. (2004) M.O.D.E.L. (Multi-user Online Dynamic Environment for Learning) - an online campus for 2010?, abstracts for ALT-C 2004. Available online at: http://www.alt.ac.uk/ altc2004 (accessed 20 November 2005).

Cornford, J. (2000) The virtual university is (paradoxically) the university made concrete, Information Communication and Society, 3(4), 508-525. 
Elliott, R. (2004) To Bb or not to Bb? That was the question, abstracts for ALT-C 2004. Available online at: http://www.alt.ac.uk/altc2004/.

Flanagan, M., et al. (2004) Designing a new kind of online discussion forum, the dialogue interface, abstracts for ALT-C 2004. Available online at: http://www.alt.ac.uk/altc2004/ (accessed 20 November 2005).

Fitzgerald, R. (2004) E-submission issues, practice and policy, abstracts for ALT-C 2004. Available online at: http://www.alt.ac.uk/altc2004/ (accessed 20 November 2005).

Gunn, C. (2004) Themed speaker opening remarks at the ALT-C 2004 Conference, Blue Skies and Pragmatism, Exeter.

Herbsleb, J. D., et al. (2002) Introducing instant messaging and chat in the workplace, Conference on Human Factors in Computing Systems, Proceedings of the SIGCHI conference on human factors in computing systems: changing our world, changing ourselves (New York, NY, ACM Press).

Jones, A. et al. (2004) Using mobile devices to support access for learners tourists and information workers, abstracts for ALT-C 2004. Available online at: http://www.alt.ac.uk/altc2004/.

Keefe, T. (2004) Alternative technologies for alternative learners: a case study describing ICT Research and Development, abstracts for $A L T-C$ 2004. Available online at: http:// www.alt.ac.uk/altc2004/.

Kumar, V. (2004) From open resources to educational opportunity, abstracts for ALT-C 2004. Available online at: http://www.alt.ac.uk/altc2004/ (accessed 20 November 2005).

McCabe, M. \& Lucas, I. (2004) Teaching and learning with interactive classrooms, abstracts for $A L T-C$ 2004. Available online at: http://www.alt.ac.uk/altc2004/ (accessed 20 November 2005).

Morrison, D. (2004) E-learning flexible frameworks and tools: is it too late?, abstracts for ALT-C 2004. Available online at: http://www.alt.ac.uk/altc2004/ (accessed 20 November 2005).

Rowsell, D. (2004) Building reflective learning journals as Moblogs, abstracts for ALT-C 2004. Available online at: http://www.alt.ac.uk/altc2004/ (accessed 20 November 2005).

Sloep, P. (2004) Themed chair closing remarks at the ALT-C 2004 Conference, Blue Skies and Pragmatism, Exeter.

Traxler, J. (2004) Using handheld computers to support study skills, abstracts for ALT-C 2004. Available online at: http://www.alt.ac.uk/altc2004/ (accessed 20 November 2005). 